\title{
The utility of dual energy computed tomography in the management of axial gout: case reports and literature review
}

\author{
Jeremy X. Wang ${ }^{1 *}$ D, Beverly Ng${ }^{1}$, Haesung Bak', David Spencer ${ }^{1,2}$, Nicholas Manolios ${ }^{1,2}$ and Peter K. K. Wong ${ }^{1,3}$
}

\begin{abstract}
Background: Severe spinal pain is an unusual presentation of gout. Due to its rarity and the difficulty of obtaining joint fluid or tissue for crystal analysis, dual energy computed tomography (DECT) may be a useful imaging modality in the management of axial gout.

Case presentation: Two patients independently presented to a major teaching hospital with severe spinal pain subsequently shown to be due to gout. The first patient presented with back pain and fevers and was initially thought to have lumbar facet joint septic arthritis. The second case presented with severe back pain. In both cases, DECT suggested monosodium urate deposition in spinal tissues as the cause of their presentation.

Conclusions: Axial gout should be considered in the differential diagnosis of severe spinal pain. A DECT study may be a useful diagnostic tool in the management of spinal gout.
\end{abstract}

Keywords: Spinal gout, Back pain, Dual energy computed tomography, Diagnosis

\section{Background}

Gout is caused by monosodium urate (MSU) crystal deposition in synovial joints and is the most common acute inflammatory arthritis [1]. Most gouty attacks present with an acute peripheral inflammatory arthritis axial involvement is less common [2]. The diagnosis of spinal gout can be challenging due to the anatomical location, making access to a diagnostic histologic sample difficult. Dual energy computed tomography (DECT) utilises $\mathrm{x}$-rays at two energy levels and provides additional information compared to a conventional CT scan regarding tissue composition, artefact reduction and image optimisation. When used as a non-invasive modality to demonstrate MSU crystal deposition, the reported sensitivity and specificity is $78-100 \%$ and 89 $100 \%$, respectively [3-7]. We present two cases of gout involving the axial skeleton in which DECT significantly assisted management.

\footnotetext{
* Correspondence: jeremy.wang.syd@gmail.com

${ }^{1}$ Department of Rheumatology, Westmead Hospital, Westmead, Sydney, NSW 2145, Australia

Full list of author information is available at the end of the article
}

\section{Case presentation}

\section{Case 1}

A 32-year old male Pacific Islander presented to the Emergency Department with recent onset acute severe lower back pain and new onset left knee pain associated with fevers and chills. There were no bowel or bladder symptoms. Past medical history included tophaceous gout and asthma. Current medications included allopurinol $300 \mathrm{mg}$ daily with variable adherence, and a salbutamol inhaler. He worked as a security officer, did not smoke and occasionally consumed alcohol. On examination, he was febrile at $38.5{ }^{\circ} \mathrm{C}$ with multiple probable tophi on the dorsum of both hands (Fig. 1a). The left knee was tender and warm with a moderate effusion. Neurological examination was unremarkable.

Initial investigations showed a peripheral neutrophilia of $21 \times 10^{9} / \mathrm{L}$ (normal range: $3.7-9.5 \times 10^{9} / \mathrm{L}$ ) and an elevated C-reactive protein (CRP) of $250 \mathrm{mg} / \mathrm{L}$ (normal range $<5 \mathrm{mg} / \mathrm{L}$ ). Serum creatinine and uric acid level were $122 \mu \mathrm{mol} / \mathrm{L}$ (normal range $60-110 \mu \mathrm{mol} / \mathrm{L}$ ) and $0.53 \mathrm{mmol} / \mathrm{L}$ (normal range $0.16-0.41 \mathrm{mmol} / \mathrm{L}$ ), respectively. Synovial fluid aspiration of the left knee was performed and $15 \mathrm{mls}$ of inflammatory-appearing synovial fluid was sent for analysis. This revealed a white cell 


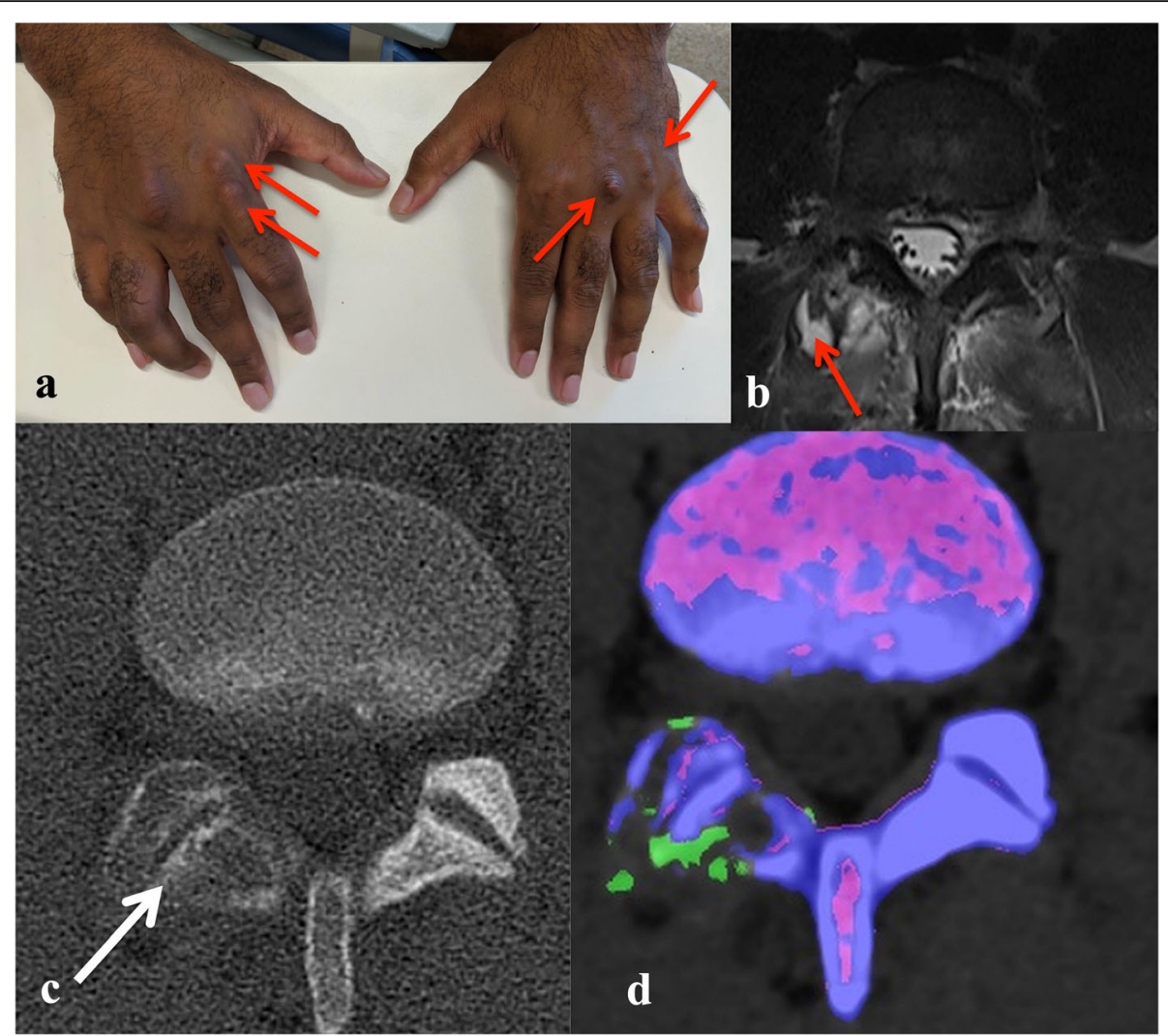

Fig. 1 a A 32-yo male Pacific Islander with probable gouty tophi affecting both hands (red arrows). b Lumbar spine MRI (T2, axial view) image reported as showing an abscess surrounding the right $L 4 / 5$ facet joint (red arrow). Axial CT image of lumbar spine showing $\mathbf{c}$ erosions (white arrow); and $\mathbf{d}$ corresponding DECT image (Siemens Somatom Force ${ }^{\mathrm{TM}}$ ) showing monosodium uric acid crystal deposition (green)

count of $33 \times 10^{9} / \mathrm{L}(100 \%$ polymorphs). Monosodium urate crystals were identified in the knee fluid and no organisms were seen on Gram stain. Subsequent culture of the knee synovial fluid and blood was negative. Magnetic resonance imaging (MRI) of the spine to investigate the severe back pain was reported as showing right L4/5 facet joint septic arthritis with abscess formation (Fig. 1b). Given the MRI report, he was empirically started on intravenous cephazolin $2 \mathrm{~g}$ every $8 \mathrm{~h}$. A CT-guided aspiration of the right L4/5 facet joint collection was performed. No organisms were seen on Gram stain of the fluid obtained. Subsequent cultures were negative, but MSU crystals were seen.

A DECT was performed to assess the extent of MSU crystal deposition in the spine (Fig. 1c, d). This showed multiple well-defined focal erosions at the right L3/4, L4/5 and L5/S1 facet joints, with dual energy attenuation characteristic of MSU deposition (Fig. 1c and d). As cultures of the knee and spinal collection fluid remained negative at $48 \mathrm{~h}$, antibiotics were stopped. Initiation of prednisone $25 \mathrm{mg}$ daily and colchicine $0.5 \mathrm{mg}$ twice daily resulted in marked improvement in back pain. Nonsteroidal anti-inflammatory drugs (NSAIDs) were not used due to the renal impairment. Allopurinol was re- initiated while he was on prednisone and up-titrated with a target serum urate level of $<0.30 \mathrm{mmol} / \mathrm{L}$.

\section{Case 2}

A 74-year old Caucasian male was admitted for investigation of acute on chronic renal failure on a background of type 2 diabetes, hypertension and ischaemic heart disease. Regular medications included carvedilol, telmisartan, hydralazine, furosemide, spironolactone, ivabradine, sitagliptin and metformin, with meloxicam as required. $\mathrm{He}$ denied recent heavy alcohol intake. On closer questioning, he reported a six-week history of lower back pain and long-standing bilateral knee pain. There was no previous history of gout. On examination, multiple lesions consistent with gouty tophi were present over the extensor aspect of both elbows and left Achilles tendon. Bilateral knee effusions with low-grade synovitis were present.

Initial investigations were as follows: serum creatinine $406 \mu \mathrm{mol} / \mathrm{L}$ (usual baseline $104 \mu \mathrm{mol} / \mathrm{L}$, normal range $60-110 \mu \mathrm{mol} / \mathrm{L}$ ), serum uric acid $0.71 \mathrm{mmol} / \mathrm{L}$ (normal range $0.16-0.41 \mathrm{mmol} / \mathrm{L}$ ) and CRP $140 \mathrm{mg} / \mathrm{L}$ (normal range $<5 \mathrm{mg} / \mathrm{L}$ ). A CT and MRI scan of the lumbar spine showed an erosive arthropathy involving the right L4/L5 facet joint associated with a partially calcified 
peri-articular mass causing marked spinal canal stenosis and compression of the descending right L5 nerve root (Fig. 2a and c).

Given the history of chronic renal disease and presence of peripheral tophi, DECT was performed which demonstrated attenuation of the soft tissue mass at the right L4/5 facet joint consistent with MSU deposition (Fig. $2 b$ and d). A diagnosis of axial gout was made. The patient was commenced on prednisone $25 \mathrm{mg}$ daily for the management of acute gout. Non-steroidal antiinflammatory drugs and colchicine were not used due to the severe renal impairment. Urate-lowering therapy with allopurinol was initiated, and febuxostat added as it was thought the target serum urate level was unable to be reached on allopurinol monotherapy. There was marked rapid symptomatic improvement. On discharge, the serum urate level was $0.35 \mathrm{mmol} / \mathrm{L}$ (normal range $0.16-0.41 \mathrm{mmol} / \mathrm{L})$.

\section{Discussion and conclusion}

Axial pain is an unusual presentation of gout. Whilst asymptomatic MSU deposition in the axial skeleton can occur in healthy subjects [8], it can also result in severe back pain [2, 9], as seen in both our cases. Most patients with axial gout have a history of tophaceous gout affecting the peripheral joints and/or hyperuricemia [9]. Both our patients had severe tophaceous gout at presentation. However, Case 2 was previously undiagnosed, possibly due to poor health literacy and lack of attendance at his general practitioner. In Case 1, poor medication adherence was responsible for accumulation of gouty tophi and the presenting severe flare.

In most published cases of spinal gout, the diagnosis was confirmed on synovial fluid analysis obtained by surgical or radiological aspiration of the lesion [2]. However, the anatomic location and limited availability of spinal surgical or interventional radiology expertise may make this challenging. Dual energy CT is a recently developed technology, which first saw clinical utility in 2005 [10]. It has better tissue characterisation and artefact reduction compared to conventional CT [10]. The reported sensitivity and specificity of DECT for detection of MSU deposition is $78-100 \%$ and $89-100 \%$, respectively [3-7]. Despite the relatively widespread use of

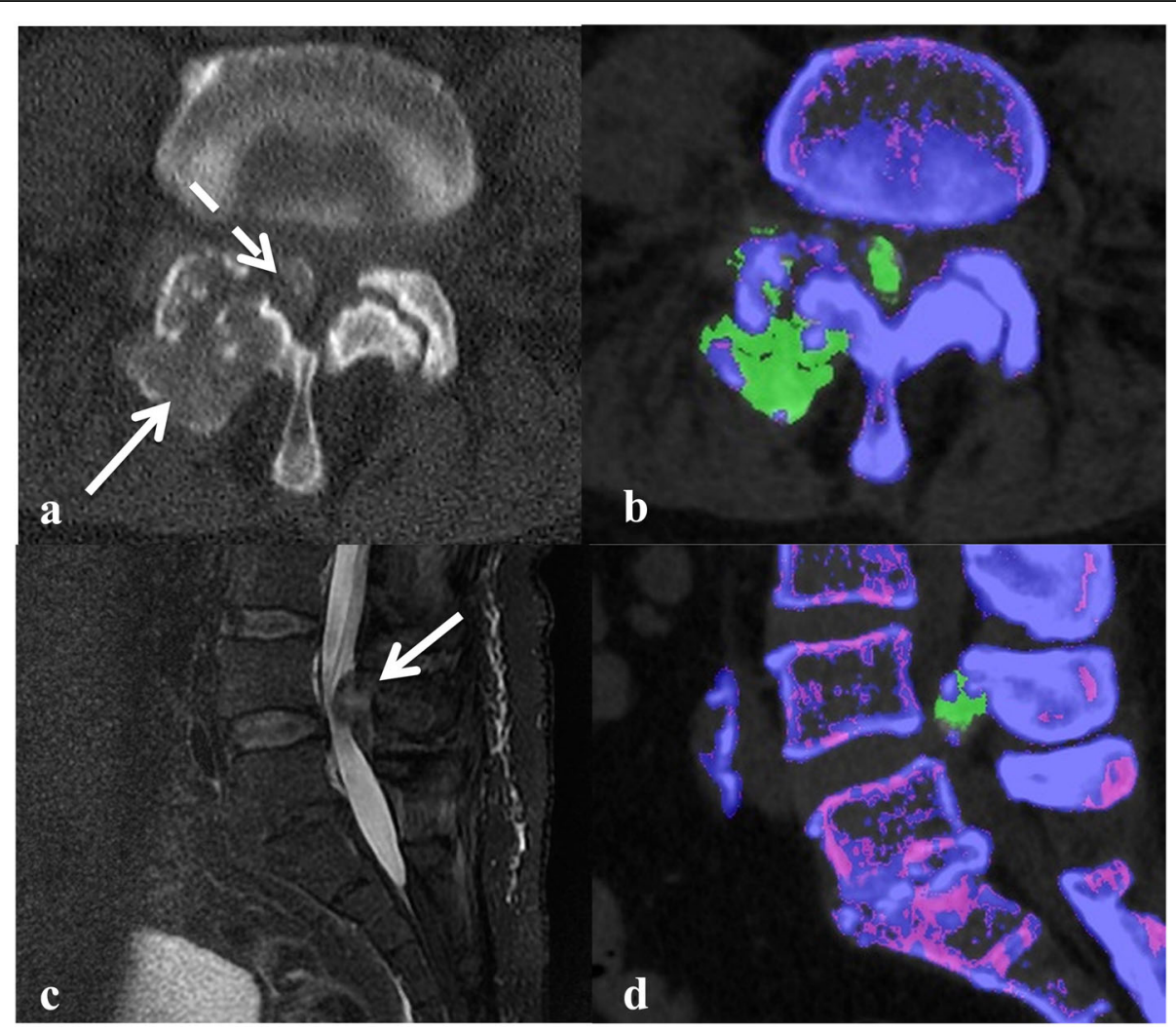

Fig. 2 a Axial $C T$ image showing right $L 4 / 5$ facet joint erosion (white arrow) with calcified peri-articular mass encroaching on lumbar canal (dashed white arrow), and $\mathbf{b}$ corresponding DECT image (Siemens Somatom Force ${ }^{\mathrm{TM}}$ ) showing monosodium uric acid crystal deposition (green). $\mathbf{c}$ Sagittal T2-fat suppressed MRI image (General Electric 1.5 T Signa Excite ${ }^{T M}$ ) of the lumbar spine showing the soft tissue mass seen in $\mathbf{a}$ and $\mathbf{b}$ causing marked lumbar canal stenosis, and $\mathbf{d}$ corresponding DECT image (Siemens Somatom Force ${ }^{\mathrm{TM}}$ ) showing attenuation consistent with monosodium uric acid crystal deposition 
DECT for detection of MSU crystals in peripheral joints, there have only been a handful of case reports of its use in spinal gout $[2,9,11-15]$. Due to the high-quality images and ability to assess soft tissue structures, MRI is often the initial imaging modality used to investigate back pain, especially in the presence of neurologic impairment. However, MRI is unable to specifically identify MSU deposition. In fact, in Case 1, the initial MRI findings suggested an incorrect diagnosis of septic arthritis. In the right clinical context, DECT could potentially avoid an invasive diagnostic aspiration/biopsy, especially in those patients who may be medically unfit due to comorbidities. For example, Case 2 did not undergo a diagnostic spinal aspirate and was successfully managed with medical therapy, as there were no clinical features of infection. However, in Case 1, the history of high fevers and chills necessitated exclusion of spinal infection by a CT-guided aspirate of the soft tissue mass (Fig. 1b).

Gout should be considered in the differential diagnosis of severe back pain - especially in the presence of a previous gouty attack and/or tophi. These two cases demonstrate the ability of DECT to detect MSU crystal deposition in the spine. Depending on the clinical setting, this can be a useful non-invasive diagnostic tool.

\section{Abbreviations \\ CRP: C-reactive protein; CT: Computed tomography; DECT: Dual energy computed tomography; MRI: Magnetic Resonance Imaging; \\ MSU: Monosodium urate; NSAID: Non-steroidal anti-inflammatory drug}

\section{Acknowledgements}

Not applicable.

\section{Authors' contributions}

JW and BN wrote the initial manuscript. BN and PKW were involved in the care of Case 1. BN and HB were involved in the care of Case 2. PKW, HB, DS, and NM critically appraised and revised the overall content of the manuscript. All authors read and approved the final manuscript.

\section{Funding}

This research received no grant from any funding agency in the public, commercial, or not-for-profit sectors.

\section{Availability of data and materials}

Not applicable.

\section{Ethics approval and consent to participate}

Not applicable.

\section{Consent for publication}

Written informed consent was obtained from the patients for publication of the case report and any accompanying images. A copy of the written consent is available for review by the Editor of this Journal.

\section{Competing interests}

The authors declare that they have no competing interests.

\section{Author details}

'Department of Rheumatology, Westmead Hospital, Westmead, Sydney, NSW 2145, Australia. ${ }^{2}$ Sydney Medical School, University of Sydney, Sydney, NSW, Australia. ${ }^{3}$ Rural Clinical School, Coffs Harbour, Faculty of Medicine, University of New South Wales, Sydney, Australia.
Received: 7 January 2020 Accepted: 11 February 2020

Published online: 08 May 2020

\section{References}

1. Kuo CF, Grainge MJ, Zhang W, Doherty M. Global epidemiology of gout: prevalence, incidence and risk factors. Nat Rev Rheumatol. 2015;11(11):64962.

2. Zhang T, Yang F, Li J, Pan Z. Gout of the axial joint-a patient level systemic review. Semin Arthritis Rheum. 2019;48(4):649-57.

3. Choi HK, Burns LC, Shojania K, Koenig N, Reid G, Abufayyah M, Law G, Kydd AS, Ouellette H, Nicolaou S. Dual energy $C T$ in gout: a prospective validation study. Ann Rheum Dis. 2012;71(9):1466-71.

4. Choi HK, Al-Arfaj AM, Eftekhari A, Munk PL, Shojania K, Reid G, Nicolaou S. Dual energy computed tomography in tophaceous gout. Ann Rheum Dis. 2009:68(10):1609-12

5. Dalbeth N, Choi HK. Dual-energy computed tomography for gout diagnosis and management. Curr Rheumatol Rep. 2013;15(1):301.

6. Glazebrook KN, Guimaraes LS, Murthy NS, Black DF, Bongartz T, Manek NJ, Leng S, Fletcher JG, McCollough CH. Identification of intraarticular and periarticular uric acid crystals with dual-energy CT: initial evaluation. Radiology. 2011;261(2):516-24.

7. Manger B, Lell M, Wacker J, Schett G, Rech J. Detection of periarticular urate deposits with dual energy $C T$ in patients with acute gouty arthritis. Ann Rheum Dis. 2012;71(3):470-2.

8. Carr A, Doyle AJ, Dalbeth N, Aati O, McQueen FM. Dual-energy CT of Urate deposits in costal cartilage and intervertebral disks of patients with Tophaceous gout and age-matched controls. AJR Am J Roentgenol. 2016; 206(5):1063-7.

9. Toprover M, Krasnokutsky S, Pillinger MH. Gout in the spine: imaging, diagnosis, and outcomes. Curr Rheumatol Rep. 2015;17(12):70.

10. Mallinson PI, Coupal TM, McLaughlin PD, Nicolaou S, Munk PL, Ouellette HA. Dual-energy CT for the musculoskeletal system. Radiology. 2016;281(3):690707.

11. Alqatari S, Visevic R, Marshall N, Ryan J, Murphy G. An unexpected cause of sacroiliitis in a patient with gout and chronic psoriasis with inflammatory arthritis: a case report. BMC Musculoskelet Disord. 2018;19(1):126.

12. Chew N, Cho J. Dual-energy $C T$ for the diagnosis of sacroiliac and spinal gout. Joint Bone Spine. 2019;86(2):259.

13. Dhaese S, Stryckers M, Van Der Meersch H, Terryn W, Van Laecke S. Gouty arthritis of the spine in a renal transplant patient: a clinical case report: an unusual presentation of a common disorder. Medicine (Baltimore). 2015; 94(13):e676

14. Parikh P, Butendieck R, Kransdorf M, Calamia K. Detection of lumbar facet joint gouty arthritis using dual-energy computed tomography. J Rheumatol. 2010;37(10):2190-1.

15. Namas R, Hegazin SB, Memisoglu E, Joshi A. Lower back pain as a manifestation of acute gouty sacroilititis: utilization of dual-energy computed tomography (DECT) in establishing a diagnosis. Eur J Rheumatol. 2019;6(4): 216-8.

\section{Publisher's Note}

Springer Nature remains neutral with regard to jurisdictional claims in published maps and institutional affiliations.
Ready to submit your research? Choose BMC and benefit from:
- fast, convenient online submission
- thorough peer review by experienced researchers in your field
- rapid publication on acceptance
- support for research data, including large and complex data types
- gold Open Access which fosters wider collaboration and increased citations
- maximum visibility for your research: over $100 \mathrm{M}$ website views per year
At BMC, research is always in progress.
Learn more biomedcentral.com/submissions 